\title{
PORE GEOMETRY AS A LIMITING FACTOR FOR ANION DIFFUSION IN
}

\section{ARGILLACEOUS ROCKS}

\section{Wigger ${ }^{1 *}$, M. Plötze ${ }^{2}$, L.R. Van Loon ${ }^{3}$}

${ }^{1}$ Laboratory for Waste Management, Paul Scherrer Institut, 5232 Villigen PSI, Switzerland ${ }^{2}$ Institute for Geotechnical Engineering, 8093 Zurich, Switzerland

${ }^{3}$ Laboratory for Waste Management, Paul Scherrer Institut, 5232 Villigen PSI, Switzerland

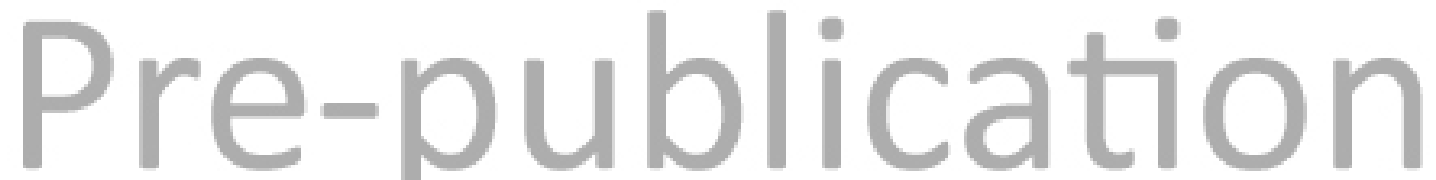

Corresponding author: Cornelia Wigger (cornelia.wigger@psi.ch)

Cornelia Wigger*

Paul Scherrer Institut

5232 Villigen PSI

Switzerland

cornelia.wigger@psi.ch

+41563105036

*corresponding author

\section{Key Points}

Bottleneck Effect, Opalinus Clay, Porosity, Retention Potential, Tortuosity

This document is the accepted manuscript version of the following article:

wigger, C., Plötze, M., \& Van Loon, L. R. (2018). Pore geometry as a limiting factor for anion diffusion in argillaceous rocks. Clays and Clay Minerals, 66(4), 329-338. https:// doi .org/10.1346/CCMN.2018.064101 
2 Several barriers are foreseen to minimize the release of radionuclides from a waste matrix into

3 groundwater. In various countries argillaceous rocks constitute the natural barrier that will

4 isolate radioactive substances from the aquifer. This study addresses the influence of the pore

5 geometry as a limitation factor for anion diffusion in argillaceous rocks. Independent of the

6 pore core size the anion diffusion can be limited by the pore size opening, i.e. if the pore opening

7 is so narrow that the electric double layers overlap and form a barrier for anions independent of

8 the pore size. This bottleneck effect limits the anion diffusion. This study extends other

9 investigations that focus on different limitation factors of anion diffusion, e.g. mineralogy or 10 interlayer equivalent pores. The existence of so-called bottleneck pores was confirmed by effective tortuosity calculations and retention potential measurements with mercury intrusion porosimetry. On the basis of two different core samples from argillaceous rocks from Switzerland, Opalinus Clay and Helvetic Marl, this work shows evidence for the existence of

bottleneck pores. The larger permanent anion exclusion in the Helvetic Marl sample compared to the Opalinus Clay sample can be explained by the larger retention potential and larger effective tortuosity of the Helvetic Marl rock, which indicates more pores with bottleneck effects than for the Opalinus Clay rock. 
In various countries argillaceous rocks have been proposed as potential host rocks for deep geological disposal of nuclear waste due to their favorable properties, such as self-sealing, excellent sorption capacity for a wide range of radionuclides, and low hydraulic conductivity restricting advective water flow towards the repository. Due to the low hydraulic conductivity, molecular diffusion is the major transport process of radionuclides from the waste matrix through the host rock towards the biosphere. Among the dose determining radionuclides, anionic species such as ${ }^{129} \mathrm{I},{ }^{36} \mathrm{Cl}$ and ${ }^{79} \mathrm{Se}$ are the most important ones because their sorption on rock minerals (in particular on the negatively charged clay minerals) is very weak or even zero (Altmann, 2008; Grambow, 2008; Tournassat and Appelo, 2011). Understanding the behavior of anions in clays and argillaceous rocks is thus very important to evaluate repository safety. Several studies were performed to investigate the sorption and transport behavior of anions in clays and clay rich materials such as bentonite (Appelt et al., 1975; Bolt and de Haan, 1979; Muurinen, 1994; Smith et al., 2004; Van Loon et al., 2007; Descostes et al., 2008; Tournassat and Appelo, 2011; Song et al., 2016; Tournassat et al., 2016a). The majority of the studies are devoted to the determination of effective and apparent diffusion coefficients and capacity factors for application in safety analyses of radioactive waste repositories. Neither the differences of the results nor their origin are properly discussed in former studies; in particular a proper experimental study of the pore characteristics influencing the anion diffusion in argillaceous rocks is still open although some works can be found (Matusewicz et al., 2013; Tournassat et al., 2016b; Gaboreou et al., 2016;Gimmi and Fernández, 2017.

Diffusion is mainly impacted by porosity, tortuosity and sorption, dictated by the density and mineralogy of the argillaceous rocks. Unlike cations and neutral species, anions are partially excluded from pores because of the permanent negative charge of clay mineral surfaces. Moreover, the extent of anion exclusion depends on the ionic composition of the pore water. A 
comparison study of different argillaceous rocks showed that the anion accessible porosity of some argillaceous rocks is more dependent on the composition of the pore water than others (Wigger and Van Loon, 2017). In the same study a permanent anion exclusion, i.e. a permanent inaccessible pore space for anions independent on the ionic strength, was observed at an ionic strength of the artificial pore water larger than $1 \mathrm{M} \mathrm{NaCl}$. At the stage of $1 \mathrm{M} \mathrm{NaCl}$ the anion accessible porosity values level off, and it can be expected that at this point the electrical double layer is almost suppressed and increases less strongly with higher values of ionic strength. This permanent exclusion value was different for the two compared clayrocks samples studied, i.e. Opalinus Clay and Helvetic Marl. While Opalinus Clay sample has a comparatively small permanent anion exclusion of $30 \%$ (as a fraction of the total porosity), Helvetic Marl sample has a permanent anion exclusion of around $70 \%$. The different values were explained by the different mineralogy of the rocks (Table 1), and the presence of interlayer equivalent (ILE) pores (Wigger and Van Loon, 2017). Interlayer equivalent pores are small pores in compacted argillaceous rocks that are small enough to have - due to overlapping electric double layers similar properties as real interlayers, and are therefore inaccessible for anions. However, although Helvetic Marl sample has a larger bulk dry density, and thus is more compacted with lower total porosity than Opalinus Clay sample (Table 1), independent pore size distribution (PSD) measurements indicated that the pores of Helvetic Marl sample were larger than those in Opalinus Clay sample (Table 1), which means less but larger pores for the Helvetic Marl sample (Houben et al., 2013, Wigger et al., 2018). The question why the permanent anion exclusion in Helvetic Marl sample is larger than in Opalinus Clay samples, although the pores are larger in size, remains an unresolved item. Therefore, the ILE theory needs to be revisited and the focus has to be changed to another approach - the bottleneck pore theory-, as suggested by Wigger et al., 2018; as an alternative interpretation of permanent anion exclusion in argillaceous rocks (Tournassat and Appelo, 2011). Similar to interlayer equivalent pores, bottleneck pores reduce the anion accessible porosity independent of the pore size and independent of the ionic strength. 
74 Not the whole pore space needs to be narrow like in ILE pores in order to cause overlapping 75 electric double layers. In the case of bottleneck pores only the pore openings are narrow $(<0.5 \mathrm{~nm})$ and the electric double layer is overlapping at the pore throat and hinders the anion transport in argillaceous rocks (Figure 1). This fact does not change significantly with increasing ionic strength and leads to a permanent anion exclusion in these pores (Tournassat and Appelo, 2011, Chagneau et al., 2015).

Hence, the diffusion data published in Wigger and Van Loon (2017) was used and performed a more detailed mercury intrusion porosimetry study on the same samples used in Wigger and Van Loon (2017) to collect more information on the pore structure of the argillaceous rocks.

83 The presented study focuses on the anion diffusion limited by the connectivity of pores caused by so-called bottleneck pores based on tortuosity calculations and retention potential measurements. 
87

\section{Samples}

The rock samples used for this study are the same samples used in an earlier study (see Wigger and Van Loon, 2017): an Opalinus Clay core sample from a deep borehole (SLA-1) in Schlattingen (Canton of Thurgau, Switzerland) at a depth of $-936.25 \mathrm{~m}$ below surface; and a Helvetic Marl core sample from a deep borehole (WLB SB4a/v) in Wellenberg (Canton of Nidwalden, Switzerland) at a depth of $-474.86 \mathrm{~m}$ below surface. Schlattingen and Wellenberg have been proposed as suitable regions for hosting a repository for high-level (HLW) and lowand intermediate-level (L/ILW) waste, respectively, in Switzerland. The differences of these two samples are interesting for a comparative study. Additionally, it is attractive that a lot of studies were already performed with these two samples and these work is therefore based on a proper database. The mineral composition of the rocks and the most important physical parameters are summarized in Table 1.

\section{Tortuosity calculation}

The diffusion of anions in argillaceous rocks is influenced by the mineralogy and the pore network geometry of the sample. The diffusion coefficients of $\mathrm{HTO}$ and ${ }^{36} \mathrm{Cl}^{-}$were measured in a former study (Wigger and Van Loon, 2017), and were used in this study for novel calculations of the geometric factors.

According to Fick's first law, the mass of a diffusing substance passing through a given crosssection per unit time is proportional to the concentration gradient, and - for a one dimensional case - is defined as:

$J=-D \cdot \frac{\partial C}{\partial x}$ 
where, $J$ is the mass flux density $\left[\mathrm{mol} \cdot \mathrm{m}^{-2} \cdot \mathrm{s}^{-1}\right], D$ is the diffusion coefficient $\left[\mathrm{m}^{2} \cdot \mathrm{s}^{-1}\right], C$ is the

109

110

111

112

113 with,

114

species concentration $\left[\mathrm{mol} \cdot \mathrm{m}^{-3}\right]$ and $\frac{\partial C}{\partial x}$ is the concentration gradient $\left[\mathrm{mol} \cdot \mathrm{m}^{-4}\right]$ (Harvey, 1996).

If the concentration within the system is changing with space and time [s], Fick's second law applies:

$\frac{\partial C}{\partial t}=D_{a} \cdot \frac{\partial^{2} C}{\partial x^{2}}$

$$
D_{a}=\frac{D}{\alpha}
$$

where, $D_{a}$ is the apparent diffusion coefficient and the rock capacity factor $\alpha$ is defined as:

$\alpha=\eta_{t}+\rho \cdot K_{d}$

where, $K_{d}$ represents the equilibrium distribution coefficient $\left[\mathrm{m}^{3} \cdot \mathrm{kg}^{-1}\right]$ and $\rho$ is the dry bulk density of the rock $\left[\mathrm{kg} \cdot \mathrm{m}^{-3}\right]$. For non-sorbing tracers, such as anions, $K_{d}=0$, and the rock capacity factor $\alpha$ equals the transport porosity $\eta_{t}$ (Van Loon and Soler, 2004).

It is necessary to modify Fick's law for the evaluation of the diffusion through a fluid in a two phase system, such as water in a porous rock. The modification is applied by redefining the diffusion coefficient, $D$, to the effective diffusion coefficient, $D_{e}$, including factors such as the porosity and the pore geometry, which is defined by a combination of tortuosity and constrictivity (Vilks and Miller, 2007).

The effective diffusion coefficient, $D_{e}$, is a kind of mass conductivity and commonly used to describe diffusive fluxes in porous media and is related to the diffusion coefficient in the pore solution, $D_{p s}\left[\mathrm{~m}^{2} \cdot \mathrm{s}^{-1}\right]$ by:

$D_{e}=\frac{\eta_{t} \cdot \delta}{\tau^{2}} \cdot D_{p s}$ 
$137 \tau_{D}^{2}=\frac{\tau^{2}}{\delta}$ as: where, $\eta_{t}$ is the transport porosity of the solid phase in which the diffusion takes place, $\delta$ is the constrictivity and accounts for the fact that the pore diameter varies along the pathway [-], and $\tau$ is the tortuosity of the sample and takes account for path lengthening [-] (Choi and Oscarson, 1996; Tevissen et al., 2004; Van Brakel and Heertjes, 1974).

The constrictivity, $\delta$, and tortuosity, $\tau$, are difficult or even impossible to determine separately (Vilks and Miller, 2007). Because of the difficulty in separating $\delta$ and $\tau$, the term effective tortuosity was introduced by Melnyk and Skeet (1986) and Katsube et al. (1986), and is defined

The effective tortuosity values can be calculated by combining equation 5 and 6 :

$$
\tau_{D}^{2}=\frac{\tau^{2}}{\delta}=\frac{\eta_{t} \cdot D_{p s}}{D_{e}}
$$

from measured values of effective diffusion coefficients, computed porosity values from bulk and grain density (assumed that $\eta_{t} \approx \eta_{t o t}$ ), and diffusion coefficients in pore solution

$D_{p s}=\frac{k_{B} \cdot T}{6 \cdot \pi \cdot \vartheta \cdot r}$

where, $k_{B}$ is the Boltzmann constant $\left[\mathrm{J} \cdot \mathrm{K}^{-1}\right], T$ is the temperature $[\mathrm{K}], \vartheta$ is the dynamic viscosity of the pore water solution $\left[\mathrm{N} \cdot \mathrm{s} \cdot \mathrm{m}^{-2}\right]$ and $r$ is the hydrodynamic radius of the diffusing species $[\mathrm{m}]$.

\section{Mercury intrusion porosimetry}

In this study, the existence of so-called bottleneck pores was experimentally evaluated by mercury intrusion porosimetry (MIP). The idea is based on the study of Wardlaw and McKellar (1981), who described pore systems that affect the trapping of non-wetting fluids, such as mercury, after pressure reduction, and discussed how the shape of the mercury injection and withdrawal curves are affected by the geometry of the pores and their connectivity. 
In a first step, the clay samples have been analyzed by MIP using a Pascal $140+440$ mercury intrusion porosimeter (Thermo Scientific ${ }^{\mathrm{TM}}$, Germany) for measuring macro- and mesopores with a radius in the range of $1.8-58000 \mathrm{~nm}$. Samples of approximately $3-5 \mathrm{~g}$ were used. For avoiding erroneous measurements caused by residual water in the sample, the argillaceous rocks have been crushed into small pieces $\left(<500 \mathrm{~mm}^{3}\right)$, then shock frozen with liquid $\mathrm{N}_{2}$ and finally applied to vacuum overnight to dry the sample as gently and efficiently as possible, avoiding changes in the pore geometry, e.g. avoid shrinking (Thompson et al., 1985).

The MIP measurements were conducted by increasing the pressure up to $400 \mathrm{MPa}$ on a rock sample immersed in the non-wetting mercury. Thus, the rate of pressure increment was controlled automatically and adjusted in a progressed procedure with lower rates at lower pressure levels and during measured intrusion processes. Mercury enters smaller voids incrementally with increasing pressure. The pore volume can be deduced from the amount of intruded mercury. The pore size is determined as a function of external pressure, which is necessary to force the liquid into a pore against the surface tension of the liquid. The calculation of the pore size distribution is based on the Washburn-equation (Washburn, 1921a; Washburn 1921b):

$r_{\text {pore }}=\frac{2 \gamma \cos \theta}{\Delta P}$

where, $r_{\text {pore }}$ is the pore throat radius, $\gamma$ the surface tension of mercury $\left(\gamma \approx 0.48 \mathrm{~N} \cdot \mathrm{m}^{-1}\right), \theta$ the contact angle between the solid and mercury $\left(\theta=147^{\circ}\right)$ and $\Delta P$ is the pressure gradient applied (Diamond, 1970; Giesche, 2006). From the first intrusion measurement the porosity can be calculated from the total injected mercury volume, as well as the pore size distribution of the sample as a function of the external pressure. In a second step, the pressure is reduced until atmospheric pressure. Because of the pressure reduction, a withdrawal process will take place and the mercury will be released. This withdrawal process is equally measured and logged as the intrusion process. The intrusion curve plots the volume change caused by increasing This is a 'pre-publication' version of an accepted article for Clays and Clay Minerals. 
pressure, while the extrusion curve represents the volume change with decreasing pressure. It can be concluded that some mercury has been permanently entrapped in the sample pore space, when the intrusion-extrusion cycle does not close when the incipient pressure is reached. The amount of the entrapped mercury can be evaluated by the difference between the intrusion and extrusion curves (Moro and Böhni, 2002). Such a hysteresis indicates the presence of bottleneck pores. The larger the hysteresis, the larger the retention potential of the sample and the more bottleneck-type pores might be expected in the sample.

After a first intrusion-extrusion cycle, a second intrusion measurement was started. Due to the fact that mercury from the first cycle remained trapped in the bottleneck pores, only the empty non-bottleneck pores become refilled in the second measurement and enable detection of the pore volume of the non-bottleneck pores.

The withdrawal efficiency $\left(W_{e}\right)$ is the ratio, expressed as a percentage, of the volume of mercury 190 withdrawn, $V_{w}$, from the sample at minimum pressure $(101.325 \mathrm{kPa})$ to the volume injected before pressure was reduced, i.e. the total volume, $V_{\text {tot }}$ :

$192 \mathrm{~W}_{e}=\frac{V_{w} \cdot 100}{V_{\text {tot }}}$

193 In this study the total volume, $V_{t o t}$, is related to the total porosity, $\eta_{\text {tot }}$, of the sample, while the 194 volume of withdrawn mercury, $V_{w}$, equals the volume of the pores with a low pore to throat size 195 ratio, $\eta_{w}$. The volume data is corrected to the compressibility and temperature-dependent 196 volume of mercury. 


\section{Tortuosity calculations based on diffusion experiments}

200

201

202

203

204

205

206

207

208

209

210

211

212

213

214

215

The effective tortuosity calculations were performed as described in the Materials and Method

Section by equation 7 . The transport porosity, $\eta_{t}$, as well as the effective diffusion coefficient, $D_{e}$, were known from previous experimental studies described in Wigger and Van Loon (2017).

For an ionic strength of the pore solution of $1 \mathrm{M} \mathrm{NaCl}$, the effective diffusion coefficient of HTO in the Opalinus Clay sample is $1.12 \cdot 10^{-11} \mathrm{~m}^{2} / \mathrm{s}$ and that of ${ }^{36} \mathrm{Cl}^{-}$is $2.25 \cdot 10^{-12} \mathrm{~m}^{2} / \mathrm{s}$. The transport porosity of HTO equals $11.4 \%$, whereas the anion transport porosity measured by ${ }^{36} \mathrm{Cl}^{-}$diffusion is $6.9 \%$ in the Opalinus Clay sample. The values are larger than the ones for the Helvetic Marl sample, where the effective diffusion coefficient of HTO is $1.06 \cdot 10^{-12} \mathrm{~m}^{2} / \mathrm{s}$ and $1.22 \cdot 10^{-13} \mathrm{~m}^{2} / \mathrm{s}$ for ${ }^{36} \mathrm{Cl}^{-}$. The transport porosity of HTO in the Helvetic Marl sample is $3 \%$ and that of ${ }^{36} \mathrm{Cl}^{-}$equals $0.85 \%$.

For calculation of the diffusion coefficients in the solution $D_{p s}$, the already known parameters $\vartheta_{p s}, \vartheta_{w}$ and $D_{w}$ were needed (equation 12):

$D_{p s} \cdot \vartheta_{p s}=\frac{k_{B} \cdot T}{6 \cdot \pi \cdot r}=D_{w} \cdot \vartheta_{w}$

$D_{p s}=\frac{D_{w} \cdot \vartheta_{w}}{\vartheta_{p s}}$

where, $k_{B}$ is the Boltzmann constant $\left(1.38 \cdot 10^{-23} \mathrm{~J} \cdot \mathrm{K}^{-1}\right), T$ is the temperature $(298.15 \mathrm{~K}), \vartheta_{p s}$ is the dynamic viscosity of $1 \mathrm{M} \mathrm{NaCl}$ pore solution $\left(9.72 \cdot 10^{-4} \mathrm{~N} \cdot \mathrm{s} \cdot \mathrm{m}^{-2}\left(\right.\right.$ Kestin et al. 1981)) $\vartheta_{w}$ is the dynamic viscosity of pure water $\left(8.91 \cdot 10^{-4} \mathrm{~N} \cdot \mathrm{s} \cdot \mathrm{m}^{-2}\right)$ and $D_{w}$ is the diffusion coefficient of HTO in water $\left(2.00 \cdot 10^{-9} \mathrm{~m}^{2} \cdot \mathrm{s}^{-1}\right)$ and for chloride in pure water $\left(2.032 \cdot 10^{-9} \mathrm{~m}^{2} \cdot \mathrm{s}^{-1}\right.$ (Flury and Gimmi, 2002)), $r$ is the hydrodynamic radius for water $1.38 \cdot 10^{-10} \mathrm{~m}$ and for chloride $1.21 \cdot 10^{-10}$ m. 
This results in a pore solution diffusion coefficient, $D_{p s}$, of about $1.85 \cdot 10^{-9} \mathrm{~m}^{2} / \mathrm{s}$ for both HTO and ${ }^{36} \mathrm{Cl}^{-}$.

Based on equation 7 , the effective tortuosity, $\tau_{D}^{2}$, could be calculated. The results are summarized in Table 2.

\section{Hg-retention potential measurements}

Figure 2 shows the cumulative pore volume $\left(\mathrm{mm}^{3} / \mathrm{g}\right)$ for the intrusion (solid line) and extrusion (dashed line) process during a mercury intrusion-extrusion cycle for Opalinus Clay and Helvetic Marl rock samples. A significant hysteresis is observable for both samples. Furthermore, the extrusion curve stops before the initial pressure is reached, i.e. both samples do not have a continuous mercury path towards the sample surface and pores remained filled with mercury.

Mercury intrusion measurements show a porosity of $29.6 \mathrm{~mm}^{3} / \mathrm{g}$ for Opalinus Clay sample and $6.9 \mathrm{~mm}^{3} / \mathrm{g}$ for Helvetic Marl sample (Table 3). Analysis from the withdrawal data gives a trapped mercury volume of $18.8 \mathrm{~mm}^{3} / \mathrm{g}$ for the Opalinus Clay sample and a trapped mercury volume of $6.3 \mathrm{~mm}^{3} / \mathrm{g}$ for the Helvetic Marl sample. That means that Opalinus Clay sample has a withdrawal efficiency, $W_{e}$, of $36.4 \%$ and Helvetic Marl sample has only a $W_{e}$ of $9.1 \%$. This would mean that the Helvetic Marl sample has a much larger Hg-retention potential than Opalinus Clay. However, it needs to be considered that the device stops measuring before atmospheric pressure is reached, hence the total withdrawal potential cannot be read out from the first measurement run. Therefore, the device was opened after the first run to ensure that the atmospheric pressure was reached and all mercury with withdrawal potential withdraws until the threshold (atmospheric pressure) is reached.

After the first intrusion-extrusion cycle, a second measurement run was started. In this case only the withdrawn pores will filled again. The total volume measured during the second measurement thus corresponds to the withdrawal volume from the first measurement. In the 
244 case of Opalinus Clay sample $11.43 \mathrm{~mm}^{3} / \mathrm{g}$ could be withdrawn, whereas for Helvetic Marl

245 sample the withdrawn volume is $1.61 \mathrm{~mm}^{3} / \mathrm{g}$. As recognizable in Table 3, the total withdrawal

246 volume, which is defined as the total volume in the second run, the retention potential of

247 Opalinus Clay sample equals 61\% (100\% - 39\%) and that of Helvetic Marl sample 77\% (100\% $248-23 \%)$

249 The withdrawal volume in the second run should be $100 \%$ if the pressure could be decreased to

250 the atmospheric pressure. However, this is not the case. As long as the apparatus is running,

251 there is always a remaining pressure which is larger than the atmospheric pressure. 


\section{Tortuosity analysis}

The effective tortuosity for $\mathrm{HTO}$ and ${ }^{36} \mathrm{Cl}^{-}$is a function of the ionic strength of the pore solution (Figure 3). In the case of HTO, the effective tortuosity has a constant value of $17.8 \pm 1.9$ for Opalinus Clay sample or $33.3 \pm 4$ for Helvetic Marl sample, and does not depend on the composition of the pore solution. From this information, and also from the fact that the HTO effective porosity is independent of the composition of the pore solution, it can be concluded that HTO is not affected by any electrical effect. Unlike HTO, in the case of ${ }^{36} \mathrm{Cl}^{-}$, the effective tortuosity clearly depends on the ionic strength of the pore solution. Even at the highest ionic strengths value the effective tortuosity is still higher than that of HTO. It can further be observed that the effective tortuosity for both HTO and ${ }^{36} \mathrm{Cl}^{-}$is higher in the case of the Helvetic Marl sample than in the case of the Opalinus Clay sample. The pathways in Helvetic Marl sample are thus more tortuous than those in Opalinus Clay sample, and the pathway of ${ }^{36} \mathrm{Cl}^{-}$is more tortuous than that of HTO.

The tortuosity depends strongly on the mineral composition of the rock and on the arrangement of the composing particles. In the case of Opalinus Clay sample, the clay mineral content is 69 wt. $\%$. The majority of the non-clay minerals are quartz (20 wt.\%) and calcite (6 wt.\%). In the case of Helvetic Marl sample, the situation is different. The non-clay mineral amount is with 74 wt.\% more than twice as high as in Opalinus Clay sample. Opalinus Clay sample can thus be seen as a clay matrix with some dispersed non-clay mineral grains whereas the Helvetic Marl sample is predominantly a non-clay matrix with clay minerals in between the grains. This potential microstructure for both Opalinus Clay and Helvetic Marl rock samples is schematically depicted in Figure 4.

The difference in microstructure and the resulting difference in connectivity/tortuosity of both rocks are mainly caused by their different microstructural framework. In Opalinus Clay, clay This is a 'pre-publication' version of an accepted article for Clays and Clay Minerals. 
minerals dominate and form the structural framework. The connectivity in Opalinus Clay sample is thus mainly dictated by the arrangement of the clay particles and not by the arrangement of the non-clay minerals. In Helvetic Marl sample non-clay minerals build the structural framework and are responsible for the connectivity/tortuosity. Due to the larger degree of compaction, cementation and grain-to-grain contact of the non-clay particles, tortuosity in the Helvetic Marl sample is larger than that in the Opalinus Clay sample (Figure 4). Moreover, as soon as non-clay mineral grains squeeze the aligned clay minerals together (Figure 5), a micro-smearing zone occurs (Schmatz et al., 2010; Hemes et al., 2015; Vrolijk et al., 2016). That means that the clay minerals are closer together and diffuse double layers overlap in all probability more than in the undisturbed zone (Figure 5). This effect leads to a more frequent occurrence of bottleneck pores in the micro-smearing zone than in the uncrushed zone. The higher probability of the presence of constricted clay mineral texture caused by the movement and realignment of grains through compaction in the Helvetic Marl sample results in more bottleneck pores than in Opalinus Clay sample (Figure 4 and Figure 5). That means that even with less but larger pores, the anion transport is limited due to small pore entries.

Wigger and Van Loon (2017) discussed the effect of ionic strength on the transport accessible porosities of anions in the framework of the electrostatic properties of the porous media. At lower ionic strength of the pore water the extent of the electric double layer on the walls of charged pores is thicker than at high ionic strength (Moors, 2005), resulting in a decreased accessible porosity for anions. Not only the accessible porosity, but also the effective tortuosity might be subject to such electrostatic effects. Overlapping of electric double layers might act as barriers for anions. The more barriers there are, the more detours are needed for anions diffusing through an argillaceous rock (Figure 5). Hence, with lower ionic strength not only the accessible porosity for anions is smaller, but also direct transport paths are limited by overlapping electric double layers. As a result, anions have to diffuse along a longer path 
compared to the clay thickness, i.e. the effective tortuosity is larger (Table 4). This also explains the dependency of the effective tortuosity of anion diffusion on ionic strength and the independency of that of the uncharged HTO, which is not limited by overlapping diffuse double

layers (Figure 3). The effective tortuosity in the case of diffusion of ${ }^{36} \mathrm{Cl}^{-}$in Helvetic Marl sample seems to decrease faster with increasing porosity than that in Opalinus Clay sample (Figure 6). Thus, the anion diffusion behavior in the Opalinus Clay sample is less sensitive to the change of electric double layer thickness, supporting the assumption that the geometry of the matrix is influencing the anion diffusion and, in this case, it is indicated that the Helvetic Marl rock sample has more narrower pore openings (i.e. bottleneck-like pores) than the Opalinus Clay rock sample.

\section{Data analysis of bottleneck effect with mercury intrusion porosimetry}

Both the hysteresis displayed by withdrawal and reinjection curves, and the early breakpoint of the extrusion curve (Figure 2), indicate that both rock samples have a retention potential. Clay rocks exhibit a pore network with different pore sizes, which are randomly arranged. As the pressure falls below the threshold for a given size, individual pores empty sequentially in the order of increasing size. Wardlaw and McKellar (1981) discussed a model in which isolated clusters of large elements occurred in a continuous network of smaller elements. Based on this insight it is assumed that, if clay samples are completely filled with mercury and then the pressure is decreased, the mercury first withdraws from the smallest pores and next withdraws progressively with increasing pore size (Wardlaw and Cassan, 1979). However, in the case of large pores connected by small pores extensive residual mercury is retained, because at the stage where pressure has been reduced below the threshold for emptying of clusters of these large pores, they have already become disconnected by "snap-off” (Figure 7). 
327 Due to the snap-off effect bottleneck pores remain filled with mercury. The whole process is observed by the pressure to pore size function (equation 9), and the hysteresis helps to quantify

329 the amount of mercury that withdraws from the bottleneck pores. From the amount of 330 withdrawn mercury obtained from the difference of total volume intruded between the $1^{\text {st }}$ and $3312^{\text {nd }} \mathrm{Hg}$-intrusion measurements, the volume of the bottleneck pores can be calculated which 332 results in $61.5 \%$ for Opalinus Clay and $76.8 \%$ for Helvetic Marl, respectively. Also, the visual analysis of the hysteresis curves indicates a more distinct hysteresis effect of the Helvetic Marl sample than the one of Opalinus Clay. This shows very plainly that Helvetic Marl rock sample has a larger bottleneck pore volume than Opalinus Clay rock sample. The analysis at pore scale $>3 \mathrm{~nm}$ could give an indication about the pore structure at the micropore scale. 
339 The goal of this work was to analyze the pore geometry of Opalinus Clay and Helvetic Marl

340

341 rock samples, hereby specifically addressing the occurrence of so-called bottleneck pores and its influence on the anion transport. Bottleneck pores limit the anion diffusion independent of the pore size and independent of the ionic strength. Due to the narrow openings of these pores the electric double layers in the pore throat overlap. Consequently, bottleneck pores behave similarly to interlayer pores and hinder anion transport in argillaceous rocks. In order to investigate the amount of bottleneck pores two different methods were used in this study: effective tortuosity calculations and $\mathrm{Hg}$-retention potential measurements. A pore network result from squashed platelets has more bottleneck pores and causes a larger effective tortuosity. The results of this investigation show that Opalinus Clay sample has a smaller effective tortuosity than Helvetic Marl sample. This could be observed both for the neutral tracer HTO as well as for the anionic tracer ${ }^{36} \mathrm{Cl}^{-}$. Additionally, independent mercury intrusion and extrusion porosimetry measurements performed in this study support the conclusion of a larger $\mathrm{Hg}$ retention potential for Helvetic Marl sample than for Opalinus Clay sample by visual analysis of the hysteresis effect and by analyzing the residual volume data. The fact that the Helvetic Marl sample has a larger Hg-retention potential than the Opalinus Clay sample corroborates the assumption that the Helvetic Marl sample has more bottleneck pores than the Opalinus Clay sample, which seems to influence in the effective tortuosity and the anion diffusion. 
359 The authors would like to thank A. Röthlisberger for assistance during the experimental work

360 at the Claylab ETH, Switzerland. The authors also wish to thank L. Kennell-Morrison, who

361 reviewed the manuscript from an English grammar perspective. This study was partially

362 financed by the Nuclear Waste Management Organization of Canada (NWMO) and the Paul

363 Scherrer Institut (PSI). 
Altmann, S. (2008) Geochemical research: A key building block for nuclear waste disposal safety cases. Journal of Contaminant Hydrology, 102(3), 174-179.

Appelt, H., Holtzclaw, K. and Pratt, P. (1975) Effect of anion exclusion on the movement of chloride through soils. Soil Science Society of America Journal, 39(2), 264-267.

Baeyens, B. and Bradbury, M. H. (2004) Cation exchange capacity measurements on illite using the sodium and cesium isotope dilution technique: effects of the index cation, electrolyte concentration and competition: modeling. Clays and Clay Minerals, 52(4), 421-431.

Bolt, G. H. and de Haan, F. A. M. (1979) Chapter 7: Anion exclusion in soil. Developments in Soil Science. Elsevier. 5(B), 233-257.

Chagneau, A. L., Tournassat, C., Steefel, C. I., Bourg, I. C., Gaboreau, S.P., Esteve, I. N., Kupcik, T., Claret, F., and Schäfer, T. (2015) Complete restriction of ${ }^{36} \mathrm{Cl}^{-}$diffusion by celestite precipitation in densely compacted illite. Environmental Science \& Technology Letters, 2(5), 139-143.

Choi, J.-W. and Oscarson, D. (1996) Diffusive transport through compacted Na-and Cabentonite. Journal of Contaminant Hydrology, 22(3), 189-202.

Descostes, M., Blin, V., Bazer-Bachi, F., Meier, P., Grenut, B., Radwan, J., Schlegel, M. L., Buschaert, S., Coelho, D., and Tevissen, E. (2008) Diffusion of anionic species in Callovo-Oxfordian argillites and Oxfordian limestones (Meuse/Haute-Marne, France). Applied Geochemistry, 23(4), 655-677.

Diamond, S. (1970) Pore size distributions in clays. Clays and clay minerals, 18(1), 7-23.

Flury, M. and Gimmi, T. F. (2002) 6.2 Solute diffusion. Methods of Soil Analysis: Part 4, 13231351.

Gaboreau, S., Robinet, J.C. and Prêt, D. (2016) Optimization of pore-network characterization of a compacted Clay material by TEM and FIB/SEM imaging. Microporous and Mesoporous Materials 224, 116-128.

Giesche, H. (2006) Mercury porosimetry: a general (practical) overview. Particle \& particle systems characterization, 23(1), 9-19.

Gimmi, T. and Fernández, A.M. (2017). Physical characterisation of pores and pore water of samples from the Schlattingen borehole. Technical Report NAB 16-71. Nagra, Wettingen, Switzerland.

Grambow, B. (2008) Mobile fission and activation products in nuclear waste disposal. Journal of Contaminant Hydrology, 102(3), 180-186.

Harvey, K. B. (1996) Measurement of diffusive properties of intact rock, Atomic Energy of Canada Ltd.

Hemes, S., Desbois, G., Urai, J. L., Schröppel, B., and Schwarz, J.-O. (2015) Multi-scale characterization of porosity in Boom Clay (HADES-level, Mol, Belgium) using a combination of X-ray $\mu$-CT, 2D BIB-SEM and FIB-SEM tomography. Microporous and mesoporous materials, 208, 1-20.

Houben, M., Desbois, G., and Urai, J. L. (2013) Pore morphology and distribution in the shaly facies of Opalinus Clay (Mont Terri, Switzerland): Insights from representative 2D BIB-SEM investigations on $\mathrm{mm}$ to $\mathrm{nm}$ scale. Applied Clay Science, 71, 82-97.

Katsube, T., Melnyk, T., and J. Hume (1986) Pore structure from diffusion in granitic rocks, Atomic Energy of Canada Limited, Whiteshell Nuclear Research Establishment.

Kestin, J., Khalifa, H. E., and Correia, R. J. (1981) Tables of the dynamic and kinematic viscosity of aqueous $\mathrm{NaCl}$ solutions in the temperature range $20-150 \mathrm{C}$ and the pressure range 0.1-35 MPa. Journal of physical and chemical reference data, 10(1), 71-88. 
Matusewick, M., Pirkkalainen, K., Liljeström, V., Suuronen, J.P., Root, A., Muurinen, A., Serimaa, R. and Olin, M. (2013). Microstructural investigation of calcium montmorillonite. Clay Minerals, 48, 267-276.

Mazurek, M., Waber, N., Mäder, U., Gimmi, T., de Haller, A., and Koroleva, M. (2012) Geochemical synthesis for the Effingen Member in boreholes at Oftringen, Gösgen and Küttigen. Technical Report NTB 12-07. Nagra, Wettingen, Switzerland.

Melnyk, T. and Skeet, A. (1986) An improved technique for the determination of rock porosity. Canadian Journal of Earth Sciences, 23(8), 1068-1074.

Moors, H. (2005) Topical report on the effect of the ionic strength on the diffusion accessible porosity of Boom Clay. SCK CEN, Mol, Belgium, report SCK A CEN-ER-02.

Moro, F. and Böhni, H. (2002) Ink-bottle effect in mercury intrusion porosimetry of cementbased materials. Journal of Colloid and Interface Science, 246(1), 135-149.

Muurinen, A. (1994) Diffusion of anions and cations in compacted sodium bentonite. VTT Publications 168, Technical Research Centre of Finland, Espoo, Finland.

Schmatz, J., Vrolijk, P., and Urai, J. (2010) Clay smear in normal fault zones-The effect of multilayers and clay cementation in water-saturated model experiments. Journal of Structural Geology, 32(11), 1834-1849.

Smith, D., Pivonka, P., Jungnickel, C., and Fityus, S. (2004) Theoretical analysis of anion exclusion and diffusive transport through platy-clay soils. Transport in porous media, 57(3), 251-277.

Song, Y., Davy, C. A., Bertier, P., and Troadec, D. (2016) Understanding fluid transport through claystones from their 3D nanoscopic pore network. Microporous and Mesoporous Materials, 228, 64-85.

Tevissen, E., Soler, J., Montarnal, P., Gautschi, A., and L. R. Van Loon (2004) Comparison between in situ and laboratory diffusion studies of HTO and halides in Opalinus Clay from the Mont Terri. Radiochimica Acta/International journal for chemical aspects of nuclear science and technology, 92(9-11/2004), 781-786.

Thompson, M. L., McBride, J. F., and Horton, R. (1985) Effects of drying treatments on porosity of soil materials. Soil science society of America journal, 49(6), 1360-1364.

Tournassat, C. and Appelo, C. A. J. (2011) Modelling approaches for anion-exclusion in compacted Na-bentonite. Geochimica et Cosmochimica Acta, 75(13), 3698-3710.

Tournassat, C., Bourg, I. C., Holmboe, M., Sposito, G., and Steefel, C. I. (2016a) Molecular dynamics simulations of anion exclusion in clay interlayer nanopores. Clays and Clay Minerals, 64(4), 374-388.

Tournassat, C., Gaboreau, S., Robinet, J.-C., Bourg, I. C., and Steefel, C. I. (2016b) Impact of microstructure on anion exclusion in compacted clay media. The Clay Mineral Society Workshop Lectures Series. 21, Chapter 11, 137-149.

Van Brakel, J. and Heertjes, P. M. (1974) Analysis of diffusion in macroporous media in terms of a porosity, a tortuosity and a constrictivity factor. International Journal of Heat and Mass Transfer, 17(9), 1093-1103.

Van Loon, L. R., Glaus, M. A., and Müller, W. (2007) Anion exclusion effects in compacted bentonites: Towards a better understanding of anion diffusion. Applied Geochemistry, 22(11), 2536-2552.

Van Loon, L. R. and Soler, J. M. (2004) Diffusion of HTO, ${ }^{36} \mathrm{CI}^{-},{ }^{125} \mathrm{I}^{-}$and ${ }^{22} \mathrm{Na}^{+}$in Opalinus Clay: Effect of Confining Pressure, Sample Orientation, Sample Depth and Temperature. Nagra Technischer Bericht NTB 03-07. Nagra, Wettingen, Switzerland, Paul-Scherrer-Institut, PSI.

Vilks, P. and Miller, N. (2007) Evaluation of experimental protocols for characterizing diffusion in sedimentary rocks. Nuclear Waste Management Organization Report TR2007-11. Nuclear Waste Management Organization, Toronto, Canada. 
Vrolijk, P. J., Urai, J. L., and Kettermann, M. (2016) Clay smear: Review of mechanisms and applications. Journal of Structural Geology, 86, 95-152.

Wardlaw, N. and Cassan, J. (1979) Oil recovery efficiency and the rock-pore properties of some sandstone reservoirs. Bulletin of Canadian Petroleum Geology, 27(2), 117-138.

Wardlaw, N. and McKellar, M. (1981) Mercury porosimetry and the interpretation of pore geometry in sedimentary rocks and artificial models. Powder technology, 29(1), 127143.

Washburn, E. W. (1921a) The dynamics of capillary flow. Physical review, 17(3), 273.

Washburn, E. W. (1921b) Note on a method of determining the distribution of pore sizes in a porous material. Proceedings of the National Academy of Sciences, 7(4), 115-116.

Wigger, C., Gimmi, T., Muller, A. C. A., and Van Loon, L. R. (2018) The influence of small pores on the anion transport properties of natural argillaceous rocks - a pore size distribution investigation of Opalinus Clay and Helvetic Marl. Applied Clay Science, 156, 134-143.

Wigger, C. and Van Loon, L. R. (2017) Importance of interlayer equivalent pores for anion diffusion in clay-rich sedimentary rocks. Environmental Science \& Technology, 51(4), 1998-2006. 

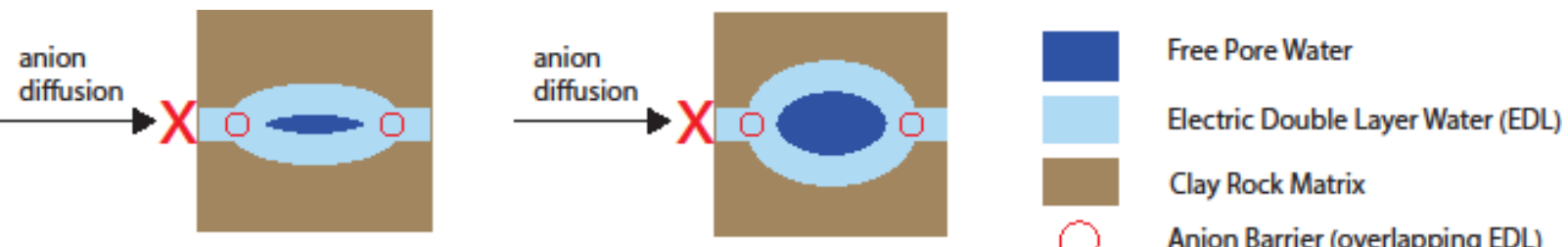

485

Figure 1 Schematic view of bottleneck pores in argillaceous rocks with overlapping electric double layers at the pore opening independent on the pore size.

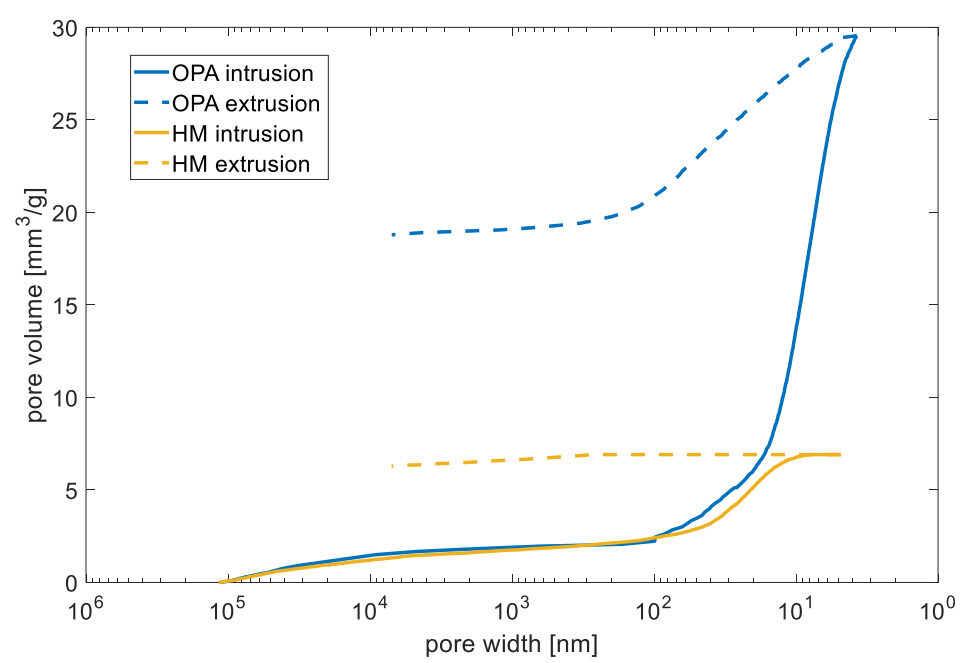

Figure 2 Intrusion and extrusion curves of a mercury intrusion porosimetry measurement for Opalinus Clay (OPA) and Helvetic Marl (HM) samples. (pore width $=$ pore diameter) 

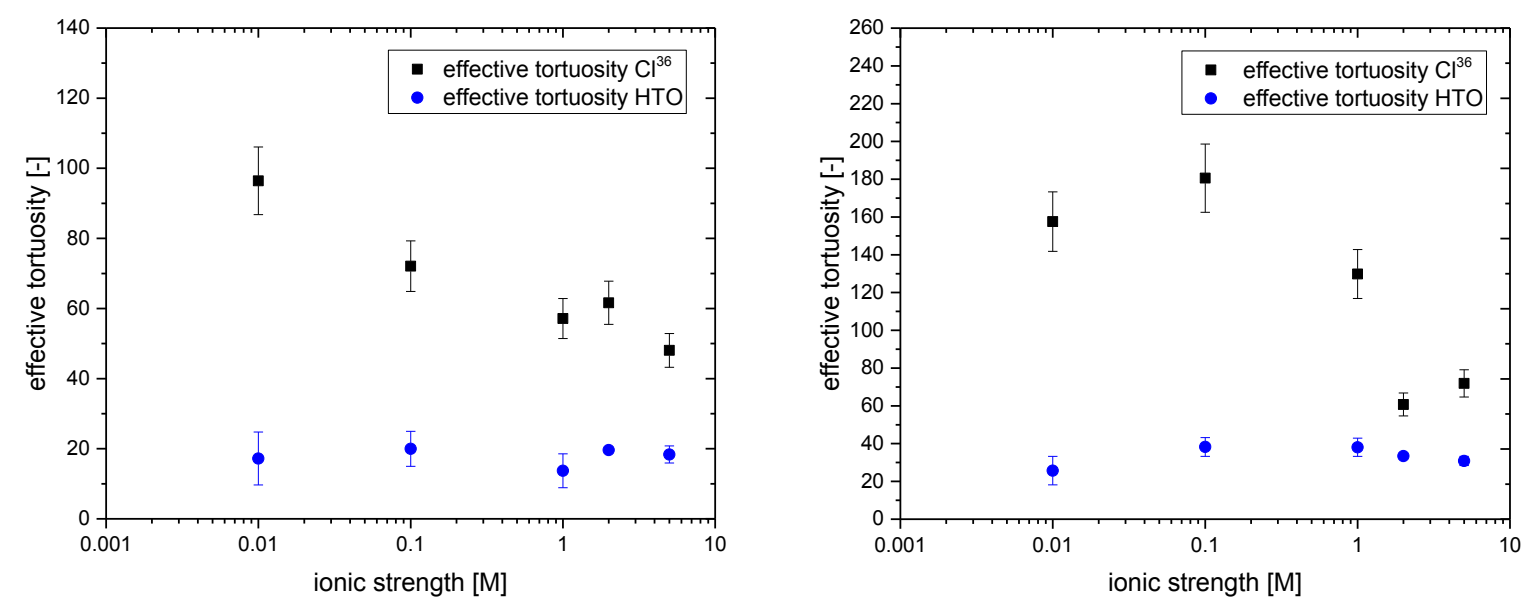

Figure 3 Effective tortuosity for the diffusion of $\mathrm{HTO}$ and ${ }^{36} \mathrm{Cl}^{-}$in Opalinus Clay (left) and Helvetic Marl (right) samples as a function of the chemical composition of the pore water.

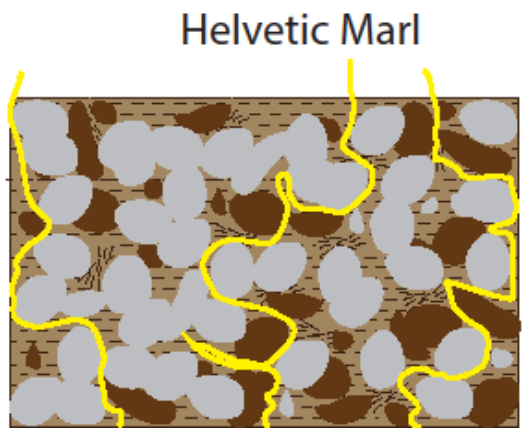

Clay matrix

Non-clay matrix

उ Diffusion Path

496

Figure 4 Cartoon picture of the microstructure and expected connectivity for Opalinus Clay and Helvetic Marl samples. 

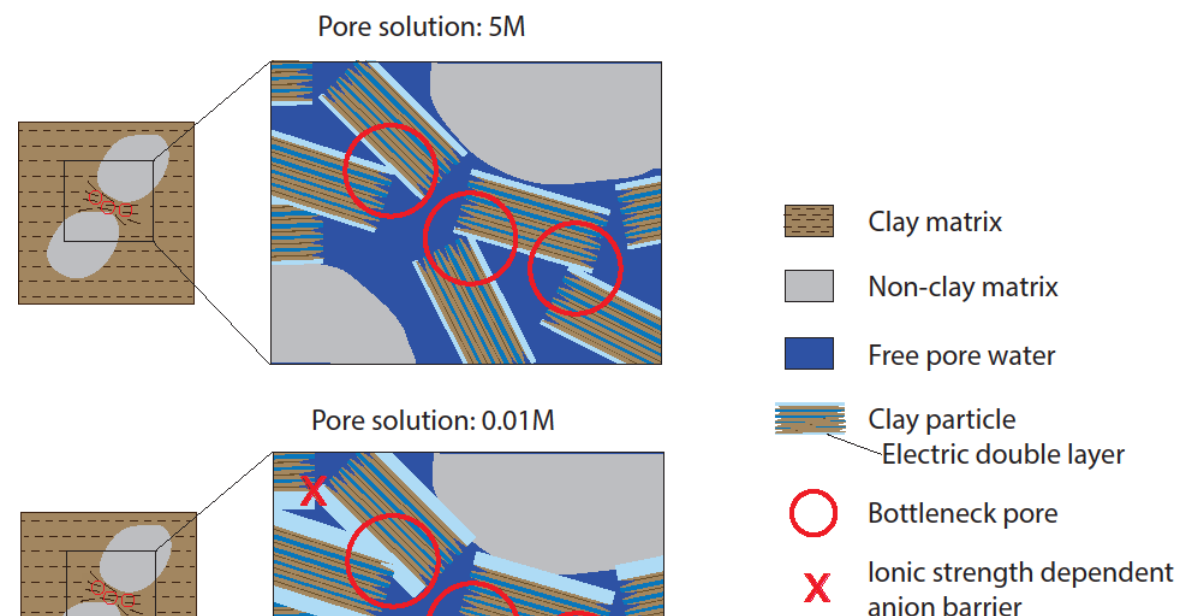

498

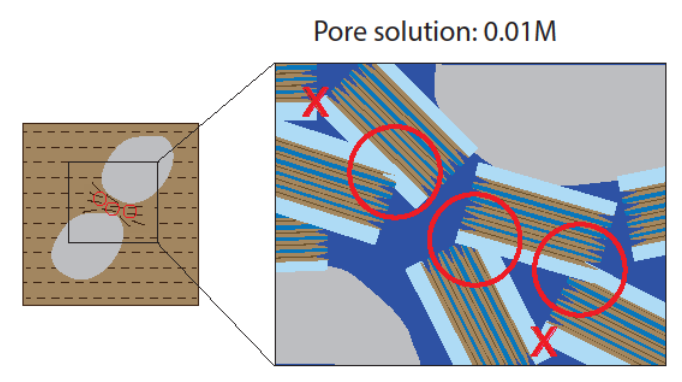
anion barrier

Figure 5 The lower the ionic strength of the pore water; the thicker are the electric double layers. Hence, there are more overlapping electric double layers acting as barriers and the anions have longer transport paths through the clay. This is more distinct in pore networks with narrow pore openings, like in the Helvetic Marl rock sample.

a)

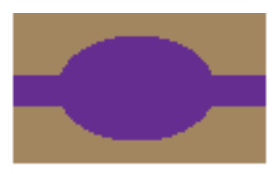

b)

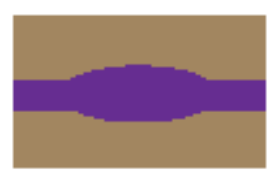

c)

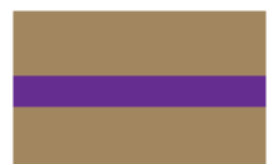

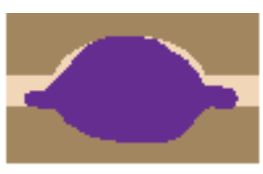
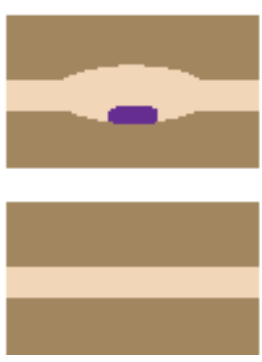

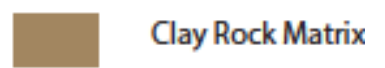

Pore

Mercury

Figure 7 Schematic view of trapped mercury in argillaceous rock pores before and after pressure reduction. a) Pore with a large pore to throat size ratio [>3] b) pore with a smaller pore to throat size ratio $[>1]$ c) pore with a small pore to throat size ratio $[\leq 1]$. (After Wardlaw and McKellar, 1981) 
Tables

Table 1 Mineralogical composition and physico-chemical properties of Opalinus Clay and Helvetic Marl rock samples used in this work (from Wigger and Van Loon, 2017).

\begin{tabular}{lcc}
\hline Parameters & Opalinus Clay & Helvetic Marl \\
\hline Sample & SLA -936.25 & WLB SB4a/v -475.86 \\
Grain density $\left(\mathrm{kg} / \mathrm{dm}^{3}\right)$ & $2.70 \pm 0.002$ & $2.73 \pm 0.001$ \\
Bulk dry density $\left(\mathrm{kg} / \mathrm{dm}^{3}\right)$ & $2.46 \pm 0.03$ & $2.66 \pm 0.03$ \\
${ }^{1}$ Total porosity $(\%)$ & $8.9 \pm 1$ & $2.6 \pm 1$ \\
${ }^{2}$ Mode pore size $(\mathrm{nm})$ & 7 & 20 \\
${ }^{3}$ CEC (meq/kg sample) & $105 \pm 0.5$ & $56 \pm 0.2$ \\
\hline${ }^{4}$ Mineralogy (wt.\%) & & $74 \pm 3$ \\
\hline Non phyllosilicates (wt.\%) & $31 \pm 3$ & 38 \\
\hline Calcite & 6 & 7 \\
Dolomite/Ankerite & $<1$ & 0 \\
Siderite & 2 & 1 \\
Na-Plagioclase & 1 & 1 \\
K-Feldspar & 2 & 25 \\
Pyrite & $<1$ & $26 \pm 3$ \\
Quartz & 20 & $<1$ \\
\hline Phyllosilicates (wt.\%) & $69 \pm 3$ & 11 \\
\hline Kaolinite & 28 & 4 \\
Illite & 25 & 11 \\
Illite-smectite & 8 &
\end{tabular}

${ }^{1}$ calculated from the grain and bulk dry density

${ }^{2}$ defined with mercury intrusion porosimetry measurements

${ }^{3}$ measured by the Cs-method (Baeyens and Bradbury 2004)

${ }^{4}$ analyzed as described in Mazurek et al. (2012)

Table 2 Summary of effective diffusion coefficients $\boldsymbol{D}_{\boldsymbol{e}}$, diffusion coefficients of pore water solution $\boldsymbol{D}_{p s}$ and porosity values $\boldsymbol{\eta}_{\boldsymbol{t}}$ obtained for Opalinus Clay and Helvetic Marl rock samples to calculate the effective tortuosity $\boldsymbol{\tau}_{\boldsymbol{D}}^{2}$ for diffusion in argillaceous rocks with $1 \mathrm{M} \mathrm{NaCl}$ pore water.

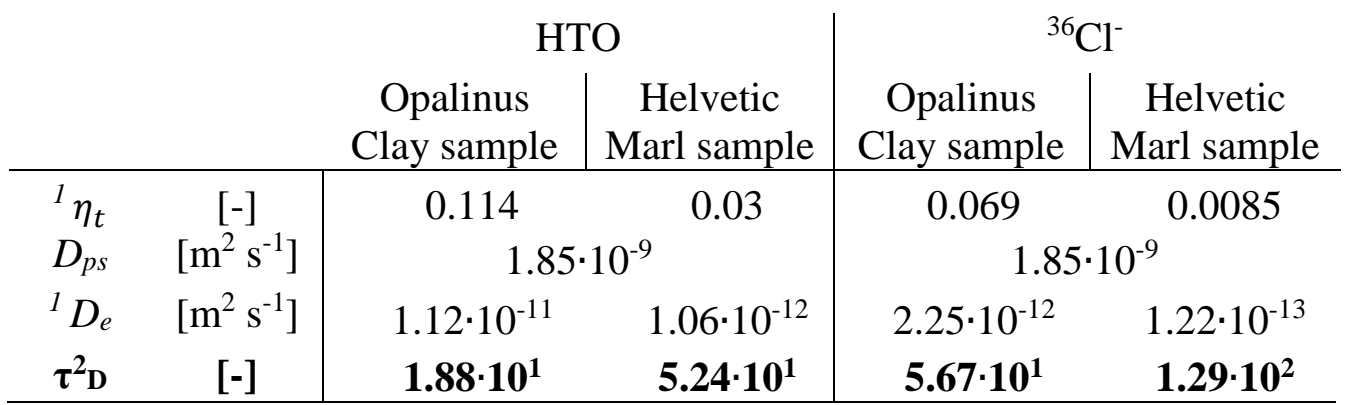


Table 3 Mercury intrusion volume data of Opalinus Clay and Helvetic Marl samples.

\begin{tabular}{|c|c|c|c|c|c|c|c|}
\hline \multicolumn{4}{|c|}{ Opalinus Clay } & \multicolumn{4}{|c|}{ Helvetic Marl } \\
\hline & {$\left[\mathrm{mm}^{3} / \mathrm{g}\right]$} & {$[\%]$} & ${ }^{1}[\%]$ & & {$\left[\mathrm{mm}^{3} / \mathrm{g}\right]$} & [\%] & ${ }^{1}[\%]$ \\
\hline $1^{\text {st }}$ run $^{2}$ & & & & $1^{\text {st }}$ run & & & \\
\hline total vol. $\left(\mathrm{V}_{\text {tot }}\right)$ & 29.6 & 100 & & total vol. $\left(\mathrm{V}_{\text {tot }}\right)$ & 6.9 & 100 & \\
\hline withdraw vol. $\left(\mathrm{V}_{\mathrm{w}}\right)$ & 10.8 & 36 & & withdraw vol. $\left(\mathrm{V}_{\mathrm{w}}\right)$ & 0.6 & 9 & \\
\hline trapped vol. ${ }^{3}$ & 18.8 & 64 & & trapped vol. & 6.3 & 91 & \\
\hline $2^{\text {nd }}$ run & & & & $2^{\text {nd }}$ run & & & \\
\hline total vol. $\left(\mathrm{V}_{\text {tot }}\right)$ & 11.4 & 100 & 39 & total vol. $\left(\mathrm{V}_{\text {tot }}\right)$ & 1.6 & 100 & 23 \\
\hline withdraw vol. $\left(\mathrm{V}_{\mathrm{w}}\right)$ & 10.6 & 93 & & withdraw vol. $\left(\mathrm{V}_{\mathrm{w}}\right)$ & 1.2 & 74 & \\
\hline trapped vol. ${ }^{3}$ & 0.8 & 7 & & trapped vol. & 0.4 & 26 & \\
\hline
\end{tabular}

\footnotetext{
${ }^{1}$ from Wigger and Van Loon (2017)

${ }^{2} 1^{\text {st }}$ run: first intrusion-extrusion cycle; $2^{\text {nd }}$ run: second intrusion-extrusion cycle;

${ }^{3}$ trapped vol.: difference of $\mathrm{Hg}$ volume from intrusion and extrusion curves;
}

Table 4 Summary of porosities $\boldsymbol{\eta}_{t}$ obtained by diffusion experiments (Wigger and Van Loon, 2017) and calculated effective tortuosity values $\boldsymbol{\tau}_{\boldsymbol{D}}^{2}$ for Opalinus Clay and Helvetic Marl samples with varying ionic strength $I$ of the pore water $(\mathrm{NaCl})$.

\begin{tabular}{|c|c|c|c|c|}
\hline & \multicolumn{4}{|c|}{${ }^{36} \mathrm{Cl}^{-}$} \\
\hline & \multicolumn{2}{|c|}{$\begin{array}{l}\text { Helvetic Marl } \\
\text { sample }\end{array}$} & \multicolumn{2}{|c|}{$\begin{array}{c}\text { Opalinus } \\
\text { Clay sample }\end{array}$} \\
\hline $\begin{array}{c}I \\
{[M]}\end{array}$ & $\eta_{t}$ & $\tau_{D}^{2}$ & $\eta_{t}$ & $\tau_{D}^{2}$ \\
\hline 0.01 & 0.0055 & 157.54 & 0.03 & 96.43 \\
\hline 0.1 & 0.0078 & 180.57 & 0.043 & 72.09 \\
\hline 1 & 0.0085 & 129.81 & 0.069 & 57.14 \\
\hline 2 & 0.0078 & 60.73 & 0.074 & 61.62 \\
\hline 5 & 0.0110 & 71.91 & 0.084 & 48.05 \\
\hline
\end{tabular}

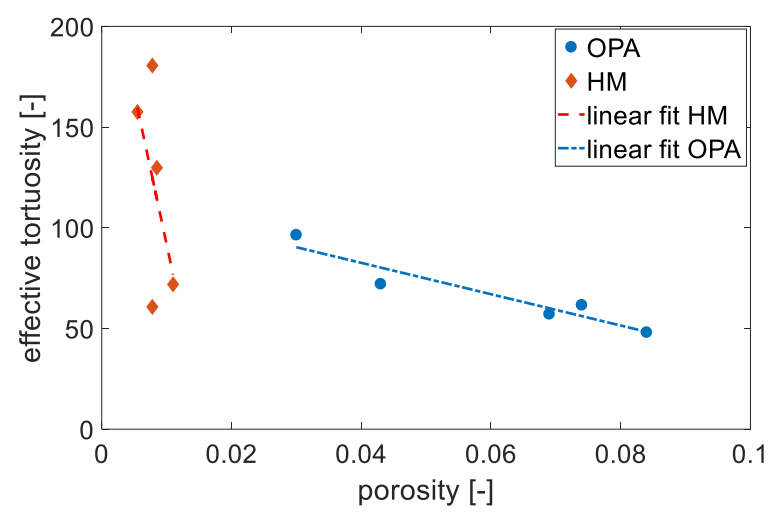

Figure 6 Effective tortuosity values of ${ }^{36} \mathrm{Cl}^{-}$ Helvetic Marl and Opalinus Clay samples plotted against the respective porosity. 


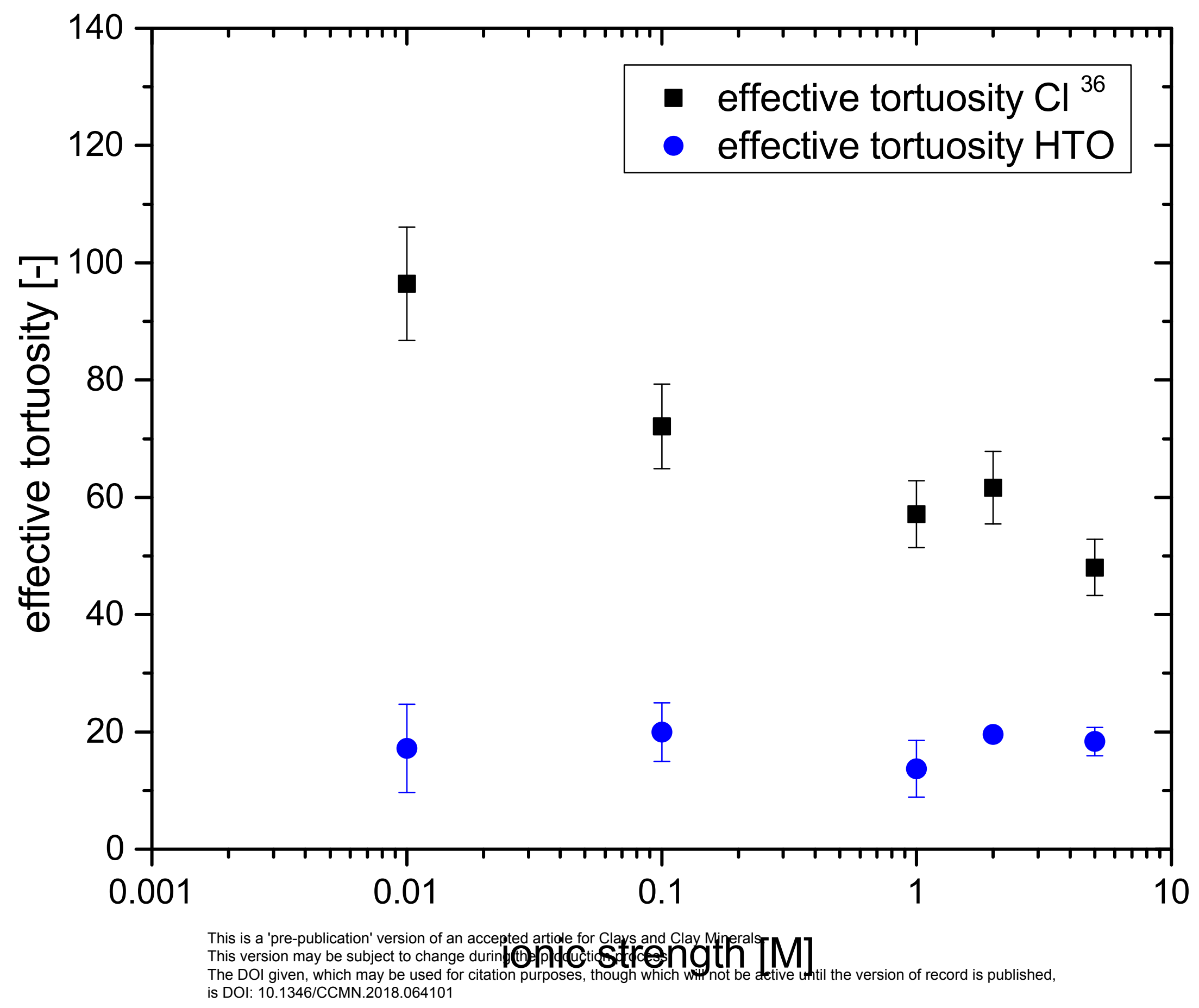




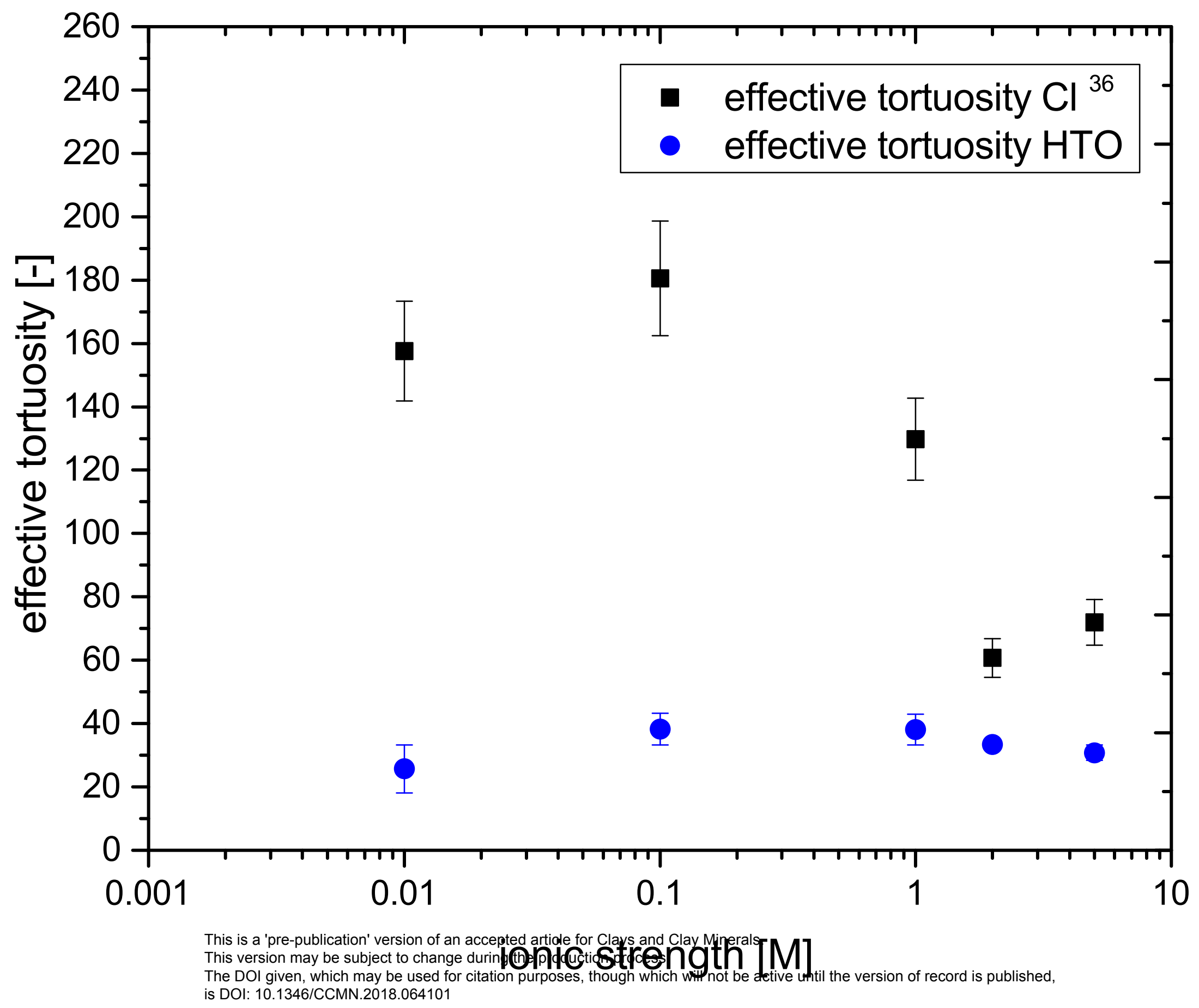


a)

b)
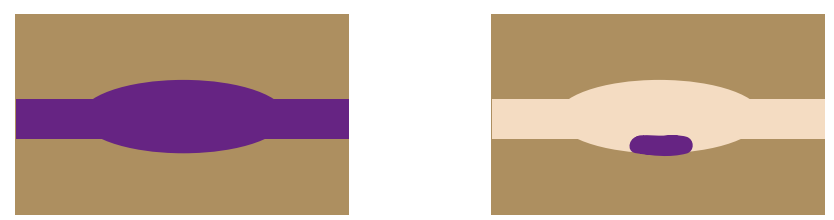

Clay Rock Matrix

\section{Pore}

Mercury

This is a 'pre-publication' version of an accepted article for Clays and Clay Minerals.

This version may be subject to change during the production process.

The DOI given, which may be used for citation purposes, though which will not be active until the version of record is published,

C) is DOI: $10.1346 /$ CCMN.2018.064101 